\title{
Lipid-based surface engineering of PLGA nanoparticles for drug and gene delivery applications
}

\author{
Rajendran JC Bose ${ }^{1,2}$, Soo-Hong Lee $2^{2^{*}}$ and Hansoo Park ${ }^{1^{*}}$
}

\begin{abstract}
The use of poly(lactic-co-glycolic acid) (PLGA)-based nanocarriers presents several major challenges, including their synthetic hydrophobic surface, low transfection efficiency, short circulation half-life, and nonspecific tissue distribution. Numerous engineering strategies have been employed to overcome these problems, with lipid-based surface functionalization of PLGA nanoparticles (NPs) showing promising results in the development of PLGA-based clinical nanomedicines. Surface engineering with different lipids enhances the target specificity of the carrier and improves its physicochemical properties as well as NP-cell associations, such as cellular membrane permeability, immune responses, and long circulation half-life in vivo. This review focuses on recent advances in the lipid-based surface engineering of PLGA NPs for drug and gene delivery applications.
\end{abstract}

Keywords: Surface engineering, Lipids, PLGA nanoparticle, Self assembly, Cell membrane derived lipid vesicles, Biomimetic fucntionalization, Controlled drug release, Gene delivery

\section{Background}

Nanotechnology has been widely studied to improve the pharmacokinetics and therapeutic efficacy of a myriad of drugs, including proteins, genes, and other small molecules [1-4]. In recent years, several therapeutics based on poly(lactic-co-glycolic acid) (PLGA) nanoparticles (NPs) (hereinafter abbreviated PNPs) have entered into preclinical development or are being investigated in biomedical research, owing to their attractive properties of biodegradability, biocompatibility, ease of processing, and sustained release [5-8]. To optimize their clinical potential, considerable efforts have been devoted to understanding the mechanism of interaction between the PNP surface and its biological environment [9]. The major barrier to the use of the PNP is its hydrophobic surface, which is often recognized as foreign material by immune cells, leading to its rapid elimination from systemic circulation [10]. In addition, this surface property of the PNP limits its cellular membrane permeability,

* Correspondence: soohong@cha.ac.kr; heyshoo@cau.ac.kr

2Department of Biomedical Science, CHA University, Seongnam-si,

Gyeonggi-do, Republic of Korea

'School of Integrative Engineering, Chung-Ang University, Seoul, Republic of Korea

(c) The Author(s). 2016 Open Access This article is distributed under the terms of the Creative Commons Attribution 4.0 International License (http://creativecommons.org/licenses/by/4.0/), which permits unrestricted use, distribution, and reproduction in any medium, provided you give appropriate credit to the original author(s) and the source, provide a link to the Creative Commons license, and indicate if changes were made. The Creative Commons Public Domain Dedication waiver (http://creativecommons.org/publicdomain/zero/1.0/) applies to the data made available in this article, unless otherwise stated. 


\section{Lipid-based surface engineering of PLGA nanoparticles}

Lipids are hydrophobic or amphiphilic molecules, present in various molecular types such as fatty acids, oils, steroids and waxes [20]. Among all, glycerophospholipids are the main component of biological membranes, which composed of a glycerol molecule linked to a phosphate group $\left(\mathrm{PO}_{4}^{2-}\right)$ and to two fatty acids [20]. These phospholipids have been widely employed for the surface engineering of PNPs. Phospholipids such as phosphatidylcholine, phosphatidylinositol, phosphatidylglycerol, phosphatidylethanolamine, phosphatidylserine, and phosphatidic acid are less stable in nature $[21,22]$. Thus their synthetic counterparts have been synthesized by modification of the nonpolar and polar regions of the phospholipid molecules [21]. Differentially charged synthetic phospholipids, such as zwitterionic, cationic, anionic, and neutral phospholipids (e.g., DOTAP, and sterol lipids such as cholesterol), are often used in biomedical engineering $[13,15]$. Polyethylene glycol (PEG) is a hydrophilic lipid that has been largely applied to improve the circulation half-life of NPs in blood [17, 18, 23, 24]. The amphiphilic nature of phospholipids allows them to form organized structures, such as vesicles or membranes, when immersed in an aqueous environment. Additionally, lipid self-assembly on the polymeric substrate depends on their surface properties, such as charge and nature of substrate (hydrophilic/hydrophobic) [16]. In general, electrostatic attraction and hydrophobic interactions are the major chemical forces responsible for the lipid self-assembly process on PNP surfaces $[17,18]$. The incorporation of anionic or cationic lipids into a phospholipid bilayer yields charged vesicles that can be adsorbed onto oppositely charged polymeric NPs via electrostatic attraction [13]. Neutral phospholipids, such as phosphatidylcholine and dipalmitoylphosphatidylcholine, adsorb and self-assemble onto hydrophobic polymeric surfaces through hydrophobic interactions in order to reduce the free energy of the system $[15,18]$. The hydrophobic tails of lipids adsorb onto the hydrophobic PNP surface, while the hydrophilic head groups of the lipids extend into the external aqueous environment, forming a lipid-monolayer-coated PNP imparting aqueous stability [15]. As more and more lipids are added to the NP dispersion, vesicles form in addition to lipid-monolayer-coated NPs $[17,18]$. The latter can interact with the vesicles via van der Waals interactions, resulting in further lipid deposition and thus increasingly larger numbers of lipid monolayers onto the PNPs [18].

Advantages in using synthetic lipids, such as DOTAP, for surface engineering of PNPs include the ease of processing and customization [13, 16]. However, adverse effects, such as the cytotoxicity of the PNPs produced and the immune responses they elicit, have fueled new surface engineering strategies, such as natural cell-membranederived lipid vesicles (nanoghosts) [10, 12, 19, 25, 26]. The motivation behind this new development lies in the fact that natural cell membrane components (i.e., lipids, proteins, and carbohydrates) have complex structures that are difficult to mimic with synthetic lipids alone [19]. Researchers have investigated various natural cellmembrane-derived nanoghosts from erythrocytes (RBCs), leukocytes, platelets, stem cells, and cancer cells for the surface engineering of PNPs [10, 12, 14, 19, 25, 26]. This cell membrane functionalized nanoparticles (CMFNPs) have the combined advantages of both cell mimetic surface and polymeric NPs [26, 27]. The lipid and protein compositions of these nanoghosts offer the unique advantage of source cell surface to the PNPs [27]. For instance, RBC-derived nanoghosts enable the PNPs to have extended the circulation half-life in vivo [10].

\section{Methods in lipid-based surface engineering of PLGA nanoparticles}

There are many methods employed for the lipid-based surface engineering of PNPs [17, 19, 28, 29]. Fig. 1 depicts different methods for fabrication of lipid-PNPs. Fabrication using synthetic lipids can be achieved by either the classical two-step method or the contemporary single-step process $[17,18]$. The selection of right method of preparation is depends on various factors such as size, shape and nature of drug incorporation with the engineered nanoparticles. In the classical twostep method, the preformed PNPs are mixed with preformed lipid vesicles, where the latter adsorb onto the polymeric NPs by electrostatic interactions [30]. Nonconventional soft lithography and spray drying methods are also applied to create PNPs of different sizes and shapes [31]. Top-down methods have been generally employed for the nanoghost-based surface engineering of PNPs, the major steps of which (including separation of cell membranes and surface engineering methods) have been briefly discussed in our recent review [19].

The nanoprecipitation and emulsification-solventevaporation (ESE) techniques can be customized for PNP preparation by the single-step method [13, 15, 16, 32]. In the single-step nanoprecipitation method, where the PLGA polymer and the lipids are either dissolved in organic solvent or the lipid and/or the lipid-PEG are dispersed in water. The PLGA polymer solution is then dropped into an aqueous phase under constant stirring, causing the precipitation of PNPs $[13,16]$. During solvent evaporation, the lipids self-assemble around the PNP core via hydrophobic interactions, with their hydrophobic tails attached to the core and their hydrophilic heads facing the external aqueous surrounding, resulting in the formation of LPHNP structures $[13,15,16,33]$. The ESE method is 
Two step method- Lipid -surface engineered PLGA NPS

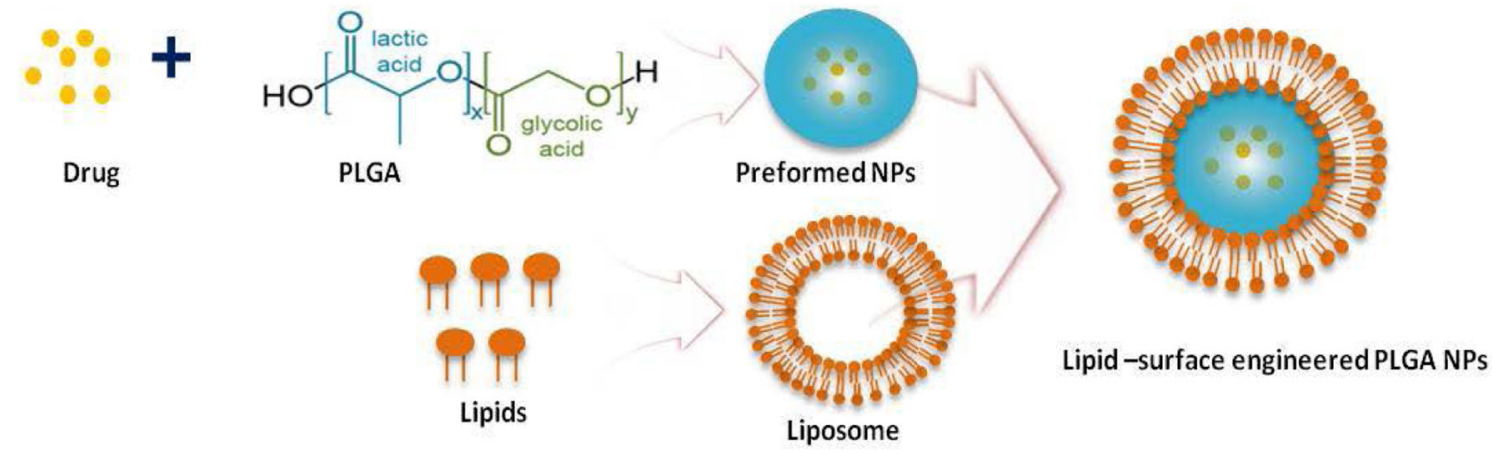

Two step method-Cell membrane derived lipid -surface engineered PLGA NPs
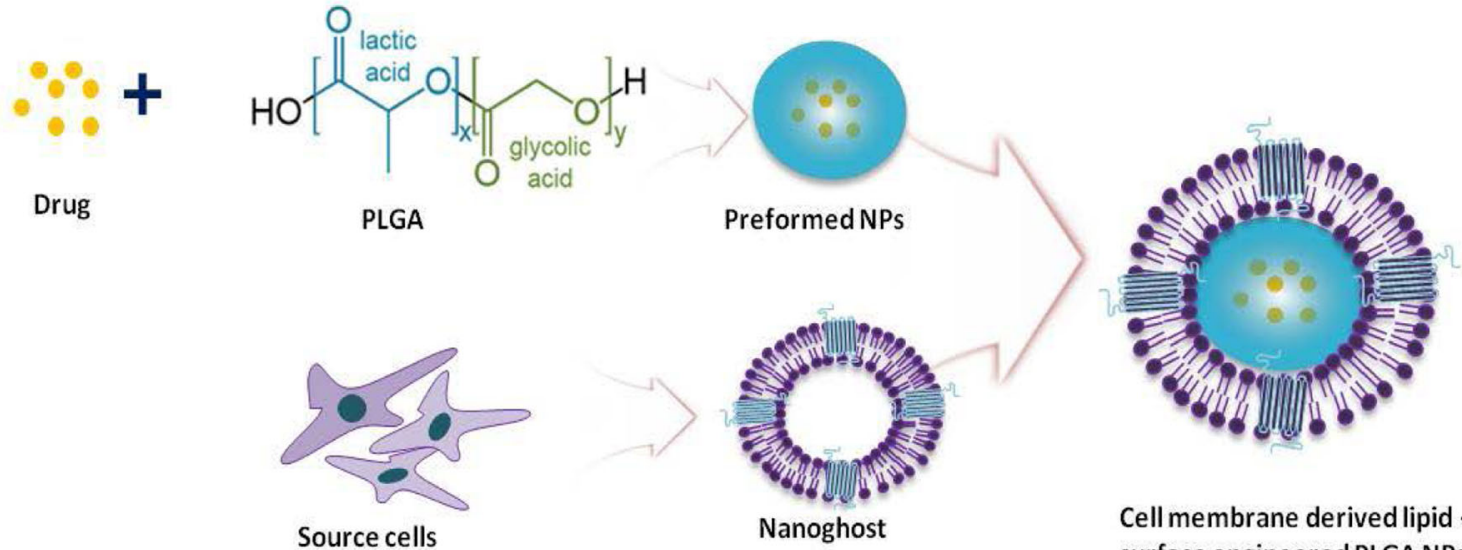

Cell membrane derived lipid surface engineered PLGA NPS

\section{One step method- Lipid -surface engineered PLGA NPS}
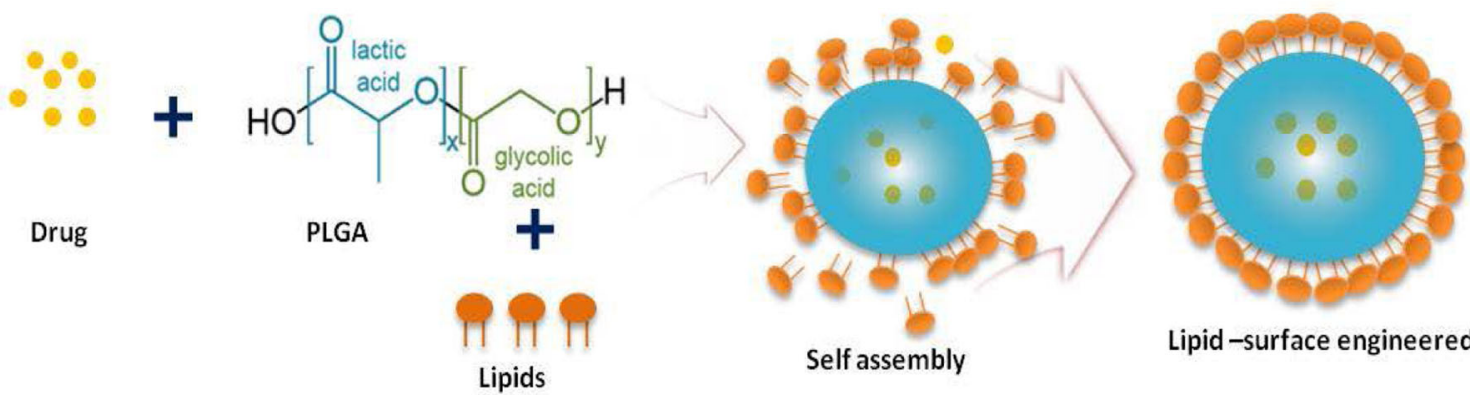

Lipid-surface engineered PLGA NPS

Fig. 1 Schematic diagram explains the different methods in the lipids based surface engineering on PLGA nanoparticles

distinguished into single and double emulsification processes. In the single ESE method, the PLGA polymeric solution is added to an aqueous phase containing the lipids to form an oil-in-water emulsion [17, 34]. In the double ESE method, the organic phase containing the PLGA polymer solution and lipids is emulsified with an aqueous buffer, and the resultant water-in-oil emulsion is further emulsified with a stabilizer or lipid-PEG to form a water-in-oil-in-water emulsion $[15,17]$. In both methods, once the organic solvent has evaporated, the PNP core is formed, around which the lipids will subsequently self-assemble, similar to the nanoprecipitation method $[15,18]$.

Selection of the correct lipid-based surface engineering method to use is crucial and depends on the nature of the lipid-PLGA surface chemistry for the desired biomedical applications [17, 18, 35]. For instance, we employed the single-step ESE method for gene delivery applications, and the nanoprecipitation method for the encapsulation and sustained release of antiproliferative agents $[13,15]$. In contrast, nanoghost-based surface engineering cannot be achieved through single-step methods, requiring 
Table 1 List of Lipid-PLGA nanoparticles and applications

\begin{tabular}{|c|c|c|c|c|c|c|c|}
\hline Lipid & $\begin{array}{l}\text { Polymeric } \\
\text { core }\end{array}$ & $\begin{array}{l}\text { Preparation } \\
\text { method }\end{array}$ & $\begin{array}{l}\text { Encapsulated } \\
\text { Drug }\end{array}$ & Size(nm) & Charge(mV) & Application & Reference \\
\hline Lecithin/DSPE-PEG & PLGA & One step & Au/QDs & $50-60$ & NA & Diagnostic/Optical imaging & [32] \\
\hline Chol & & & Curcumin & 203 & $-0.67 \pm 1.23$ & Cancer therapy & [34] \\
\hline EPC, DOPE-Tf/TPGS & & & $\begin{array}{l}\text { Aromatease } \\
\text { Inhibitor }\end{array}$ & $150-190$ & $-18 \pm 2$ & Cancer therapy & [56] \\
\hline $\begin{array}{l}\text { Lecithin, DMPE,DTPA/ } \\
\text { DSPE-PEG }\end{array}$ & & & $\begin{array}{l}\text { Docetaxel, } \\
{ }^{90} \mathrm{Y}_{,}{ }^{111} \mathrm{In}\end{array}$ & 65 & 35 & Cancer therapy & [57] \\
\hline Lecithin/DSPE-PEG & & & $\begin{array}{l}\text { Paclitaxel - } \\
\text { Gemcitabine }\end{array}$ & $70 \pm 1$ & $-51 \pm 2$ & Cancer therapy & [58] \\
\hline Lecithin/DSPE-PEG & & & Paclitaxel & $55 \pm 1$ & NA & $\begin{array}{l}\text { Treatment of coronary artery } \\
\text { disease }\end{array}$ & [59] \\
\hline DSPE-PEG & & & docetaxel & 25 & -10 & Cancer therapy & [60] \\
\hline EPC DSPE-PEG & & Two step & siRNA & $225 \pm 8$ & -10 & Gene Delivery & [61] \\
\hline FA-QLCS,Chol, PEG-OQLS & & & Paclitaxel & $184 \pm 7$ & $22 \pm 4$ & $\begin{array}{l}\text { Targeted nanoparticle for cancer } \\
\text { therapy }\end{array}$ & [62] \\
\hline Chol, DOTAP, DSPE-PEG & & & BSA & $\sim 144$ & $+4-6$ & Vaccine delivery & [63] \\
\hline \multirow[t]{2}{*}{ DOPC,DOTAP, DSPE-PEG } & & One step & Sirolimus & $\begin{array}{l}174 \pm \\
9.6\end{array}$ & $-14 \pm 0.3$ & $\begin{array}{l}\text { Sustained antiproliferative therapy } \\
\text { for the treatment of restenosis }\end{array}$ & [13] \\
\hline & & & Propolis & $\begin{array}{l}183 \pm \\
13.7\end{array}$ & $-21 \pm 2.08$ & & \\
\hline \multirow[t]{2}{*}{ DOTAP } & & & Sirolimus & $\begin{array}{l}201 \pm \\
10.3\end{array}$ & $36 \pm 6.5$ & & \\
\hline & & & Propolis & $\begin{array}{l}205 \pm \\
9.4\end{array}$ & $14 \pm 4.1$ & & \\
\hline \multirow[t]{2}{*}{ DOPC } & & & Sirolimus & $\begin{array}{l}201 \pm \\
8.8\end{array}$ & $-24 \pm 1.2$ & & \\
\hline & & & Propolis & $212 \pm 11$ & $-32 \pm 2.5$ & & \\
\hline \multirow[t]{2}{*}{ DOPC,DOTAP } & & & Sirolimus & $\begin{array}{l}186 \pm \\
8.6\end{array}$ & $-12 \pm 3.5$ & & \\
\hline & & & Propolis & $\begin{array}{l}194 \pm \\
11.7\end{array}$ & $-19 \pm 2.4$ & & \\
\hline DOTAP (6 \%) & & One step & pDNA & $\begin{array}{l}209 \pm \\
10.4\end{array}$ & $36 \pm 5.4$ & Gene delivery & [15] \\
\hline DOTAP (12 \%) & & & & $\begin{array}{l}186 \pm \\
7.9\end{array}$ & $49 \pm 2.3$ & & \\
\hline DOTAP (18 \%) & & & & $\begin{array}{l}163 \pm \\
5.6\end{array}$ & $57 \pm 2.5$ & & \\
\hline DOTAP (24 \%) & & & & $\begin{array}{l}154 \pm \\
5.2\end{array}$ & $64 \pm 3.2$ & & \\
\hline RBC membranes & & Two step & Doxorubicin & $70-90$ & $-10 \pm 2.7$ & Long circulating carrier & [44] \\
\hline \multirow[t]{2}{*}{ Platelet membranes } & & & Docetaxel & $\begin{array}{l}113.4 \pm \\
1.2\end{array}$ & $-29.5 \pm 1.2$ & $\begin{array}{l}\text { Natural targeted drug delivery. } \\
\text { Long circulating carrier }\end{array}$ & [26] \\
\hline & & & Vancomycin & $\begin{array}{l}200.3 \pm \\
3.1\end{array}$ & $-30.2 \pm 1.0$ & & \\
\hline Cancer cell membranes & & & NA & $\sim 110$ & $-35 \pm 5$ & $\begin{array}{l}\text { Natural cancer targeted drug } \\
\text { delivery. Whole cell cancer vaccine }\end{array}$ & [64] \\
\hline Monocyte membranes & & & Doxorubicin & $\begin{array}{l}\sim 150- \\
180\end{array}$ & -16.5 & $\begin{array}{l}\text { Natural cancer targeted drug } \\
\text { delivery }\end{array}$ & [14] \\
\hline $\begin{array}{l}\text { Adipose derived Stem } \\
\text { cell membranes }\end{array}$ & & & VEGF & $100-150$ & $-15 \pm 1.3$ & $\begin{array}{l}\text { Natural targeted drug delivery. Stem cell } \\
\text { mimetic nanocarrier }\end{array}$ & [12] \\
\hline
\end{tabular}


a conventional two-step top-down approach instead [10, $12,25,26]$. A list of LPHNP studies that employ the twostep and single-step methods are provided in Table 1 . Because of the perceived advantages of LPHNPs over other existing hybrid systems, significant effort has been made to understand their basic structure [36]. LPHNPs commonly comprise a hydrophobic PNP core, a lipid monolayer or bilayer surrounding the core, and a lipid-PEG corona [18]. Fig. 2 depicts the advantage of different lipid surface engineering on PNPs.

\section{Applications of lipid-based surface-engineered PLGA nanoparticles}

Drug delivery

The different surface engineering methods available for producing LPHNPs have enabled the incorporation of an extensive range of drugs, regardless of their properties (e.g., water solubility and ionicity) [17, 37, 38]. LPHNPs have been demonstrated as a promising drug delivery platform owing to their greater biomimetic and biodegradable abilities, with customized targeting features $[17,39]$. The selection of lipids allows for further customization of PNPs with desired drug delivery features, such intracellular drug delivery or extended circulation with target-specific localization $[15,31]$. The lipids on the PNP surface can act as a biocompatible fence to control the drug-releasing kinetics and improve the therapeutic efficacy of the drug [13]. Recently, our research group applied this strategy to improve the antiproliferative efficacy of a drug in an in vitro system, where the effects of a higher drug concentration and of the synthetic polymeric surface of the drug-eluting stent were reported for stent-associated thrombosis [40]. Fig. 3 show the effect of different lipids on properties of lipidPLGA nanoparticles (LPHNPs) for sirolimus or propolis delivery. In Fig. 3, the schematic diagram show the method of preparation of drug encapsulated LPHNPs and its characterization including the morphology, release kinetics and inhibitory effect of sirolimus or propolis -LPHNSs on HASMCs proliferation. We demonstrated that different lipid-based surface engineering techniques used to produce sirolimus/propolis-loaded PNPs significantly improved the antiproliferative efficacy of the drugs against smooth muscle cells, while reducing the drugmediated cytotoxicity on endothelial cells.

Classically, PEG lipids have been employed to improve the biodistribution and circulation half-life of PNPs, as the PEG corona provides steric stabilization and acts as a protective layer $[41,42]$. Recently, however, PNPs engineered with RBC-membrane-derived nanoghosts were demonstrated to be better biomimetic long-circulating nanocarriers than PEG-based PNPs [10, 43]. Moreover, Aryal et al. demonstrated that the $\mathrm{RBC}$ nanoghosts on the PNP surface could act as a diffusion barrier to better control the drug release, as compared with PEG-based PNPs, thereby enhancing the therapeutic efficacy of the drug in acute myeloid leukemia cells [44].

Bare PNPs have the major drawback of nonspecific target localization, resulting in uncontrolled tissue distribution of the drug. To improve the PNPs' site-specific localization, various strategies have been employed [10]. Lipid-based surface engineering allows for target functionalization of PNPs through either conjugation chemistry or by conferring upon them cell-membrane-mediated

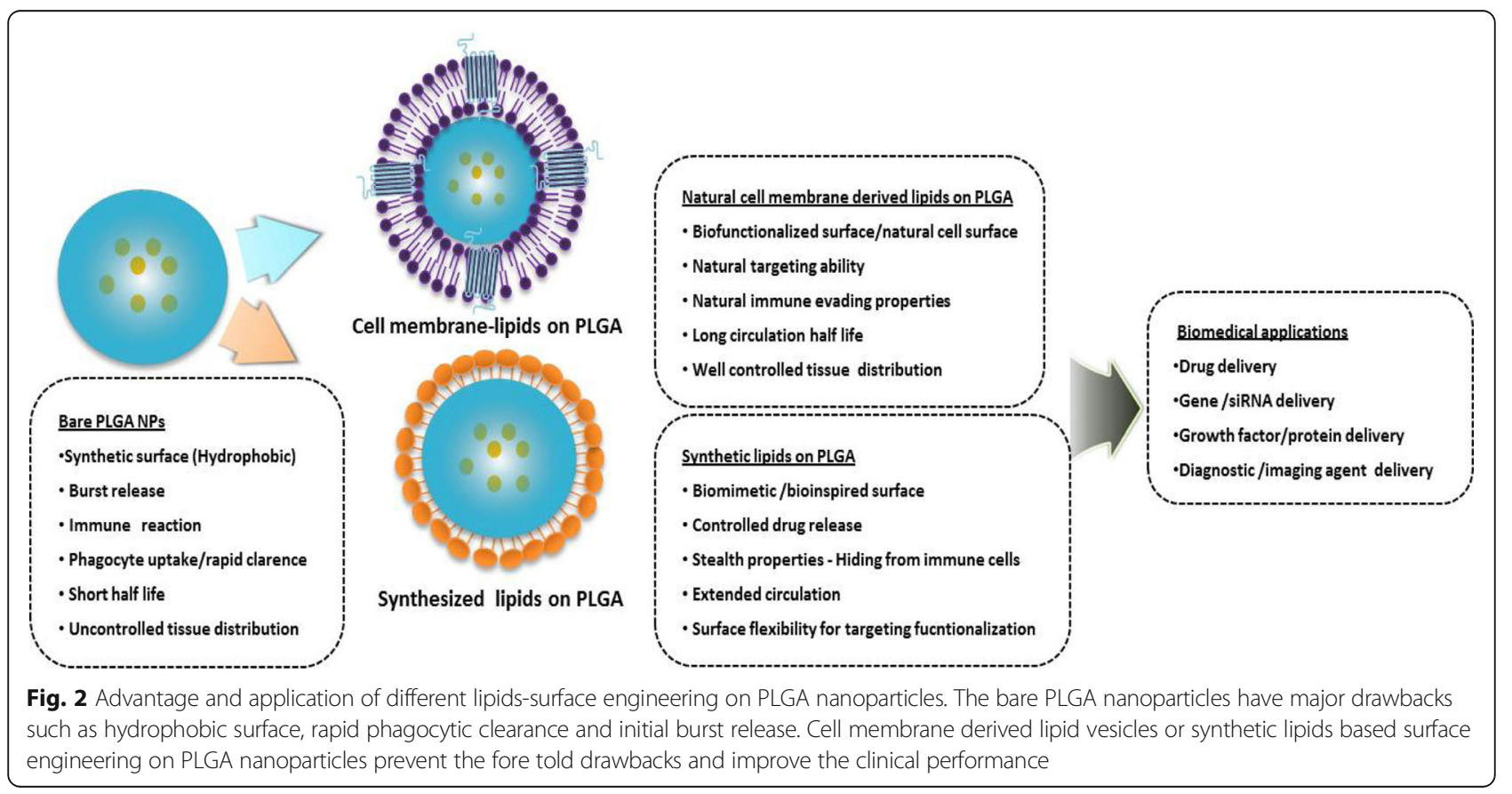




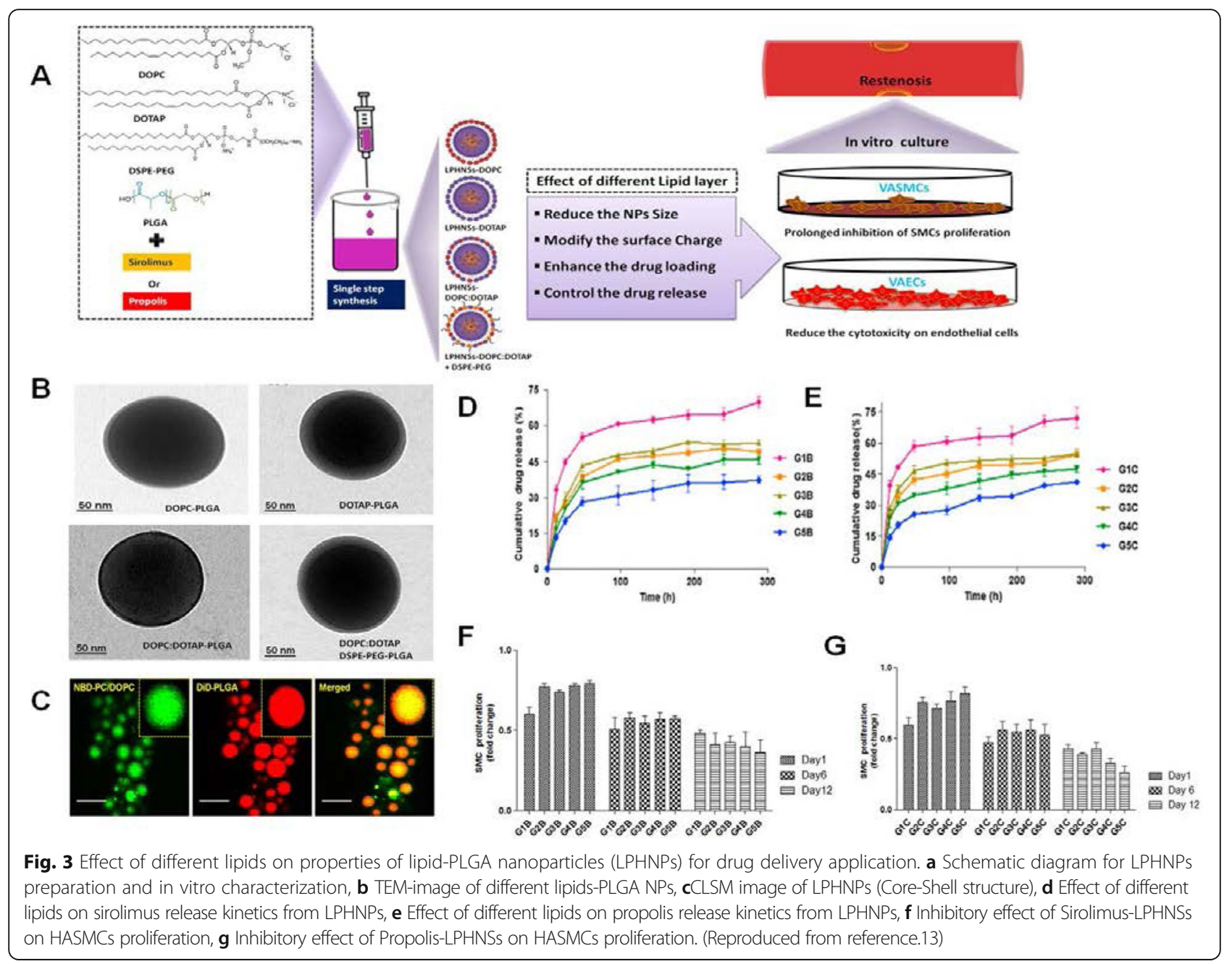

natural targeting capabilities [26, 45, 46]. Because target functionalization by various conjugation chemistries has already been reviewed by several authors, we focus here instead on the cell-membrane-mediated approach.

Cell-membrane-derived nanoghosts have the combined advantages of synthetic and biological features for improved target specificity and drug efficacy $[14,19]$. Thus, nanoghost-based surface engineering has been actively used to target PNPs to the diseased sites [10, 14, 19]. For instance, Fang et al. demonstrated a significant enhancement of the natural binding ability of drug-loaded PNPs to the source cancer cells owing to the presence of adhesion molecules [46, 47]. Correspondingly, platelet cells have a natural ability to home in on injured blood vessels as well as circulating pathogens. Thus, surface engineering of PNPs with platelet-membrane-derived nanoghosts provides them with the natural platelet-like targeting functions $[26,48]$. Krishnamurthy et al. demonstrated that the monocyte-membrane-derived nanoghost-based surface engineering of DOX-loaded PNPs resulted in higher cytotoxicity in MCF-7 breast cancer cells $[14,19,49]$. In addition, the multicompartmental nature of LPHNPs has an advantage, in that multiple therapeutic agents can be incorporated into the different compartments of the NPs $[17,18,50]$. Altogether, LPHNPs have been employed mostly for numerous drug delivery applications. The list is quite extensive and we therefore provide only the most recent applications in Table 1.

\section{Gene delivery}

Although traditional nonviral delivery systems such as liposomes and polyethylenimine (PEI) have been confirmed to be effective in in vitro and in vivo models, their clinical potential is drastically limited because of their instability and higher cytotoxicity upon systemic administration [51]. LPHNPs have emerged as a novel nonviral gene delivery system owing to their improved stability and low cytotoxicity profiles. In particular, cationic lipid (DOTAP)-layered PNPs have numerous advantages over lipoplex (liposome)-, polyplex (PEI)-, and viral-based vectors, such as their large-DNA incorporation ability, higher transfection efficiency with 
mild cytotoxicity, and feasibility for pilot-scale production $[18,52]$.

As illustrated in Fig. 4, we investigated the effect of DOTAP lipid on properties of lipid-PLGA nanoparticles (LPHNPs) for gene delivery application. We demonstrated the strong influence of DOTAP concentration on the surface properties of the LPHNPs, impacting their plasmid DNA-binding capacity, cytotoxicity, and transfection efficiency in HeLa, HaCaT, HEK293T, and HepG2 cells $[11,15]$. However, the use of LPHNPs to reduce nonspecific protein binding has not been well investigated. At present, studies on cationic LPHNP-DNA complexes are still in their infancy, and most investigations have focused only on nanocarrier preparation and characterization.

\section{Conclusions}

Lipid-based surface engineering of PNPs offers several advantages in the development of drug and gene delivery platforms, including a broad range of flexible strategies and ease of surface engineering, as well as extended circulation half-life, better target specificity, reduced cytotoxicity, and improved transfection efficiency of the nanocarriers $[13,36,53]$. Collectively, all of these features make the lipid-based surface engineering strategies ideal for improving the clinical performance of PNPs $[18,24]$. Although enormous progress has been made in the area of nanoengineering, many challenges remain that potentially hinder the translation of PNPs to the clinical arena [5, 54]. Lipid-based surface engineering can be further optimized to improve the clinical outcomes of PNPs in drug and gene delivery applications [55]. Precise control of the surface engineering with different lipids as well as of their concentration on PNPs is critical in gene delivery, as these factors directly influence the efficiency of nanocarriers $[15,51]$.

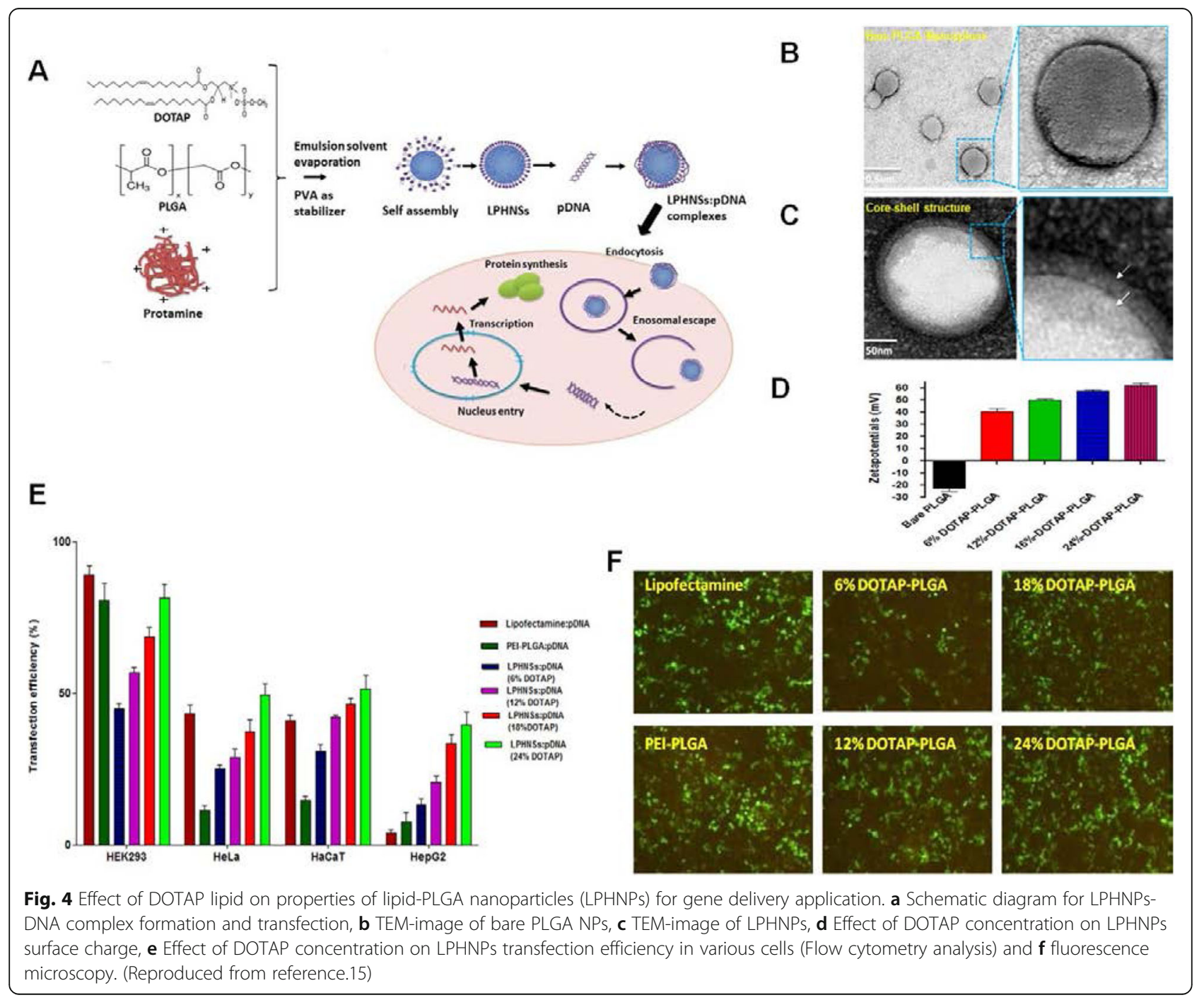




\section{Abbreviations}

DOPC: 1, 2-dioleoyl-sn-glycero-3-phosphocholine ESE, emulsificationsolvent-evaporation; DOTAP: 1, 2-dioleoyl-3-(trimethyl ammonium) propane; DOX: Doxorubicin; DSPE-PEG: 1, 2-distearoyl-sn-glycero-3phosphoethanolamineN-[methoxy-(polyethyleneglycol)-2000] (ammonium salt); HaCaT: Human keratinocyte cell Line; HEK293T: Human embryonic kidney 293 cells; HeLa: Human cervical cancer cell line; HepG2: Human hepatocellular carcinoma cell line; LPHNPs: Lipid-PLGA hybrid nanoparticles; pDNA: Plasmid deoxyribonucleic acid; PLGA: Poly(lactic-co-glycolic acid);

\section{Acknowledgement}

This work was supported by the Basic Science Research Program through the National Research Foundation of Korea (NRF) funded by the Ministry of Education (NRF-2013R1A1A1076136) and the Ministry of Science, ICT \& Future Planning (NRF-2016R1A2A1A05004987)

\section{Availability of data and materials}

Not applicable.

\section{Authors' contributions}

RJCB and HP conceptually designed the review article together. SHL and HP drafted and reviewed all sections. All authors read and approved the final manuscript.

\section{Competing interests}

The authors declare that they have no competing interests.

\section{Consent for the publication}

Not applicable.

\section{Ethics approval and consent to participate}

Not applicable.

Received: 19 July 2016 Accepted: 11 October 2016

Published online: 31 October 2016

\section{References}

1. Farokhzad OC, Langer R. Nanomedicine: developing smarter therapeutic and diagnostic modalities. Adv Drug Deliv Rev. 2006;58:1456-9.

2. Li L, Huh KM. Polymeric nanocarrier systems for photodynamic therapy. Biomater Res. 2014:18:1.

3. Bose RJC, Soo-Hong L, Park H. Fabrication and characterization of PLGA polymer-lipid hybrid nanoparticle for gene delivery platform, The Polymer Society of Korea Proceedings of 2014 Spring Conference paper. 2014. p. 60.

4. Udomluck N, Baipaywad P, Lee S-H, Park H. Poly (N-isopropylacrylamide)based nanogels encapsulating gold nanoparticles for DNA delivery. J Control Release. 2015;213:e85.

5. Danhier F, Ansorena E, Silva JM, Coco R, Le Breton A, Préat V. PLGA-based nanoparticles: an overview of biomedical applications. J Control Release. 2012;161:505-22.

6. Duraisamy K, Kalaiyarasi D, Bose R, Jaganathan K. Evaluation of m-cell targeted lectin anchored PLGA nanoparticles for oral immunization against hepatitis B infections. In: J Gastroenterol Hepatol. NJ: WileyBlackwell; 2012. p. 155-6.

7. Yang J, Li Y, Jin S, Xu J, Wang PC, Liang X-J, Zhang X. Engineered biomaterials for development of nucleic acid vaccines. Biomater Res. 2015;19:1

8. Chen C, Bang S, Cho Y, Lee S, Lee I, Zhang S, Noh I. Research trends in biomimetic medical materials for tissue engineering: 3D bioprinting, surface modification, nano/micro-technology and clinical aspects in tissue engineering of cartilage and bone. Biomater Res. 2016;20:1.

9. Krishnakumar D, Kalaiyarasi D, Bose J, Jaganathan K. Evaluation of mucoadhesive nanoparticle based nasal vaccine. J Pharm Investigation. 2012:42:315-26.

10. Hu C-MJ, Zhang L, Aryal S, Cheung C, Fang RH, Zhang L. Erythrocyte membrane-camouflaged polymeric nanoparticles as a biomimetic delivery platform. Proc Natl Acad Sci. 2011;108:10980-5.

11. Bose RJC, Ahn JC, Yoshie A, Park S, Park H, Lee SH. Preparation of cationic lipid layered PLGA hybrid nanoparticles for gene delivery. Journal of controlled release: official journal of the Controlled Release Society. 2015; 213:e92-3.
12. Bose RJC, Kim BJ, Lee SH, Park H. Surface modification of polymeric nanoparticles with human adipose derived stem cell membranes AdMSCs, 10th World Biomaterials Congress Abstract. Front Bioeng Biotechnol. 2016. doi:10.3389/conf.FBIOE.2016.01.01711.

13. Bose RJC, Lee SH, Park H. Lipid polymer hybrid nanospheres encapsulating antiproliferative agents for stent applications. Journal of Industrial and Engineering Chemistry. 2016;36:284-92.

14. Krishnamurthy S, Gnanasammandhan MK, Xie C, Huang K, Cui MY, Chan JM. Monocyte Cell Membrane-derived Nanoghosts for Targeted Cancer Therapy. Nanoscale. 2016;8(13):6981-5.

15. Bose RJC, Yoshie A, Ahn JC, Park H, Lee SH. Influence of cationic lipid concentration on properties of lipid-polymer hybrid nanospheres for gene delivery. Int J Nanomedicine. 2015;10:5367-82.

16. Zhang L, Chan JM, Gu FX, Rhee J-W, Wang AZ, Radovic-Moreno AF, Alexis F, Langer R, Farokhzad OC. Self-assembled lipid - polymer hybrid nanoparticles: a robust drug delivery platform. ACS Nano. 2008;2:1696-702.

17. Hadinoto K, Sundaresan A, Cheow WS. Lipid-polymer hybrid nanoparticles as a new generation therapeutic delivery platform: a review. Eur J Pharm Biopharm. 2013:85:427-43.

18. Mandal B, Bhattacharjee H, Mittal N, Sah H, Balabathula P, Thoma LA, Wood GC. Core-shell-type lipid-polymer hybrid nanoparticles as a drug delivery platform. Nanomed Nanotechnol Biol Med. 2013;9:474-91.

19. Bose RJC, Lee SH, Park H. Biofucntionalized nanoparticles:an emerging drug delivery platform for various disease treatments. Drug Discov Today. 2016; 21(8):1303-12.

20. Monteiro N, Martins A, Reis RL, Neves NM. Liposomes in tissue engineering and regenerative medicine. J R Soc Interface. 2014;11:20140459.

21. Eibl H, Kaufmann-Kolle P. Medical application of synthetic phospholipids as liposomes and drugs. J Liposome Res. 1995;5:131-48.

22. van Hoogevest $P$, Wendel $A$. The use of natural and synthetic phospholipids as pharmaceutical excipients. Eur J Lipid Sci Technol. 2014;116:1088-107.

23. Jokerst JV, Lobovkina T, Zare RN, Gambhir SS. Nanoparticle PEGylation for imaging and therapy. Nanomedicine. 2011;6:715-28.

24. Clawson C, Ton L, Aryal S, Fu V, Esener S, Zhang L. Synthesis and characterization of lipid-polymer hybrid nanoparticles with pH-triggered poly (ethylene glycol) shedding. Langmuir. 2011;27:10556-61.

25. Hu C-MJ, Fang RH, Luk BT, Chen KN, Carpenter C, Gao W, Zhang K, Zhang L. 'Marker-of-self'functionalization of nanoscale particles through a top-down cellular membrane coating approach. Nanoscale. 2013;5:2664-8.

26. Hu C-MJ, Fang RH, Wang K-C, Luk BT, Thamphiwatana S, Dehaini D, Nguyen P, Angsantikul P, Wen CH, Kroll AV. Nanoparticle biointerfacing by platelet membrane cloaking. Nature. 2015;526:118-21.

27. Yoo J-W, Irvine DJ, Discher DE, Mitragotri S. Bio-inspired, bioengineered and biomimetic drug delivery carriers. Nat Rev Drug Discov. 2011;10:521-35.

28. Kim Y, Lee Chung B, Ma M, Mulder WJ, Fayad ZA, Farokhzad OC, Langer R. Mass production and size control of lipid-polymer hybrid nanoparticles through controlled microvortices. Nano Lett. 2012;12:3587-91.

29. Yang $X-Z$, Dou S, Wang $Y-C$, Long H-Y, Xiong M-H, Mao C-Q, Yao Y-D, Wang J. Single-step assembly of cationic lipid-polymer hybrid nanoparticles for systemic delivery of siRNA. ACS Nano. 2012;6:4955-65.

30. Sengupta S, Eavarone D, Capila I, Zhao G, Watson N, Kiziltepe T, Sasisekharan R. Temporal targeting of tumour cells and neovasculature with a nanoscale delivery system. Nature. 2005;436:568-72.

31. Hasan W, Chu K, Gullapalli A, Dunn SS, Enlow EM, Luft JC, Tian S, Napier ME, Pohlhaus PD, Rolland JP. Delivery of multiple siRNAs using lipid-coated PLGA nanoparticles for treatment of prostate cancer. Nano Lett. 2011;12:287-92.

32. Mieszawska AJ, Gianella A, Cormode DP, Zhao Y, Meijerink A, Langer R, Farokhzad OC, Fayad ZA, Mulder WJ. Engineering of lipid-coated PLGA nanoparticles with a tunable payload of diagnostically active nanocrystals for medical imaging. Chem Commun. 2012;48:5835-7.

33. Fang RH, Aryal S, Hu C-MJ, Zhang L. Quick synthesis of lipid - polymer hybrid nanoparticles with low polydispersity using a single-step sonication method. Langmuir. 2010;26:16958-62.

34. Lee J-J, Lee SY, Park J-H, Kim D-D, Cho H-J. Cholesterol-modified poly (lactide-co-glycolide) nanoparticles for tumor-targeted drug delivery. Int J Pharm. 2016:509(1-2):483-91.

35. Cheow WS, Hadinoto K. Factors affecting drug encapsulation and stability of lipid-polymer hybrid nanoparticles. Colloids Surf B: Biointerfaces. 2011;85: 214-20.

36. Zhang L, Zhang L. Lipid-polymer hybrid nanoparticles: synthesis, characterization and applications. Nano Life. 2010;1:163-73. 
37. Cheow WS, Chang MW, Hadinoto K. The roles of lipid in anti-biofilm efficacy of lipid-polymer hybrid nanoparticles encapsulating antibiotics. Colloids Surf A Physicochem Eng Asp. 2011;389:158-65.

38. Birajdar MS, Lee J. Sonication-triggered zero-order release by uncorking core-shell nanofibers. Chem Eng J. 2016;288:1-8.

39. Arumugam $S$, Sreedhar $R$, Thandavarayan RA, Karuppagounder V, Watanabe K. Targeting fatty acid metabolism in heart failure: is it a suitable therapeutic approach? Drug Discov Today. 2016;21:1003-8.

40. Luderer F, Löbler M, Rohm HW, Gocke C, Kunna K, Köck K, Kroemer HK, Weitschies W, Schmitz K-P, Sternberg K. Biodegradable sirolimus-loaded poly (lactide) nanoparticles as drug delivery system for the prevention of in-stent restenosis in coronary stent application. J Biomater Appl. 2011;25:851-75.

41. Alexis F, Pridgen E, Molnar LK, Farokhzad OC. Factors affecting the clearance and biodistribution of polymeric nanoparticles. Mol Pharm. 2008:5:505-15.

42. Perry JL, Reuter KG, Kai MP, Herlihy KP, Jones SW, Luft JC, Napier M, Bear JE, DeSimone JM. PEGylated PRINT nanoparticles: the impact of PEG density on protein binding, macrophage association, biodistribution, and pharmacokinetics. Nano Lett. 2012;12:5304-10

43. Rao L, Bu LL, Xu JH, Cai B, Yu GT, Yu X, He Z, Huang Q, Li A, Guo SS. Red Blood Cell Membrane as a Biomimetic Nanocoating for Prolonged Circulation Time and Reduced Accelerated Blood Clearance. Small. 2015; 11:6225-36

44. Aryal S, Hu C-MJ, Fang RH, Dehaini D, Carpenter C, Zhang D-E, Zhang L. Erythrocyte membrane-cloaked polymeric nanoparticles for controlled drug loading and release. Nanomedicine. 2013:8:1271-80.

45. Fang RH, Hu C-MJ, Chen KN, Luk BT, Carpenter CW, Gao W, Li S, Zhang D-E, Lu W, Zhang L. Lipid-insertion enables targeting functionalization of erythrocyte membrane-cloaked nanoparticles. Nanoscale. 2013;5:8884-8.

46. RHe A. Cancer Cell Membrane-Coated Nanoparticles for Anticancer Vaccination and Drug Delivery. Nano Lett. 2014;14:2181-8.

47. Duraisamy K, Jaganathan K, Bose JC. Methods of detecting cervical cancer. Adv Biol Res. 2011;5:226-32.

48. Anselmo AC, Modery-Pawlowski CL, Menegatti S, Kumar S, Vogus DR, Tian LL, Chen M, Squires TM, Sen Gupta A, Mitragotri S. Platelet-like nanoparticles: mimicking shape, flexibility, and surface biology of platelets to target vascular injuries. ACS Nano. 2014;8:11243-53.

49. Parodi A, Quattrocchi N, van de Ven AL, Chiappini C, Evangelopoulos M, Martinez JO, Brown BS, Khaled SZ, Yazdi IK, Enzo MV. Biomimetic functionalization with leukocyte membranes imparts cell like functions to synthetic particles. Nat Nanotechnol. 2013:8:61.

50. $Y-k$ G, Winnik FM. Strategies in biomimetic surface engineering of nanoparticles for biomedical applications. Nanoscale. 2012;4:360-8.

51. Zhong Q, Chinta D, Pamujula S, Wang H, Yao X, Mandal TK, Luftig RB. Optimization of DNA delivery by three classes of hybrid nanoparticle/DNA complexes. J Nanobiotechnol. 2010;8:6.

52. Shi J, Xiao Z, Votruba AR, Vilos C, Farokhzad OC. Differentially charged hollow core/shell lipid-polymer-lipid hybrid nanoparticles for small interfering RNA delivery. Angew Chem Int Ed. 2011;50:7027-31.

53. Dudia A, Koçer A, Subramaniam V, Kanger JS. Biofunctionalized Lipid Polymer Hybrid Nanocontainers with Controlled Permeability. Nano Lett. 2008:8:1105-10.

54. Subbiah R, Suhaeri M, Hwang MP, Kim W, Park K. Investigation of the changes of biophysical/mechanical characteristics of differentiating preosteoblasts in vitro. Biomater Res. 2015;19:1.

55. Luk BT, Zhang L. Cell membrane-camouflaged nanoparticles for drug delivery. J Control Release. 2015;220:600-7.

56. Zheng Y, Yu B, Weecharangsan W, Piao L, Darby M, Mao Y, Koynova R, Yang X, Li H, Xu S. Transferrin-conjugated lipid-coated PLGA nanoparticles for targeted delivery of aromatase inhibitor 7a-APTADD to breast cancer cells. Int J Pharm. 2010;390:234-41.

57. Wang AZ, Yuet K, Zhang L, Gu FX, Huynh-Le M, Radovic-Moreno AF, Kantoff PW, Bander NH, Langer R, Farokhzad OC. ChemoRad nanoparticles: a nove multifunctional nanoparticle platform for targeted delivery of concurrent chemoradiation. Nanomedicine. 2010;5:361-8.

58. Aryal S, Hu CMJ, Zhang L. Combinatorial Drug Conjugation Enables Nanoparticle Dual-Drug Delivery. Small. 2010;6:1442-8.

59. Chan JM, Rhee J-W, Drum CL, Bronson RT, Golomb G, Langer R, Farokhzad OC. In vivo prevention of arterial restenosis with paclitaxel-encapsulated targeted lipid-polymeric nanoparticles. Proc Natl Acad Sci. 2011;108:19347-52.
60. Dehaini D, Fang RH, Luk BT, Pang Z, Hu C-MJ, Kroll AV, Yu CL, Gao W, Zhang L. Ultra-small lipid-polymer hybrid nanoparticles for tumorpenetrating drug delivery. Nanoscale. 2016;8:14411-9.

61. Shi J, Xiao Z, Votruba AR, Vilos C, Farokhzad OC. Differentially charged hollow core/shell lipid-polymer-lipid hybrid nanoparticles for small interfering RNA delivery. Angew Chem. 2011;123:7165-9.

62. Zhao P, Wang H, Yu M, Liao Z, Wang X, Zhang F, Ji W, Wu B, Han J, Zhang $H$. Paclitaxel loaded folic acid targeted nanoparticles of mixed lipid-shell and polymer-core: in vitro and in vivo evaluation. Eur J Pharm Biopharm. 2012;81:248-56

63. Hu Y, Hoerle R, Ehrich M, Zhang C. Engineering the lipid layer of lipid-PLGA hybrid nanoparticles for enhanced in vitro cellular uptake and improved stability. Acta Biomater. 2015;28:149-59.

64. Fang RH, Hu C-MJ, Luk BT, Gao W, Copp JA, Tai Y, O'Connor DE, Zhang L. Cancer cell membrane-coated nanoparticles for anticancer vaccination and drug delivery. Nano Lett. 2014;14:2181-8.

\section{Submit your next manuscript to BioMed Central and we will help you at every step:}

- We accept pre-submission inquiries

- Our selector tool helps you to find the most relevant journal

- We provide round the clock customer support

- Convenient online submission

- Thorough peer review

- Inclusion in PubMed and all major indexing services

- Maximum visibility for your research

Submit your manuscript at www.biomedcentral.com/submit
) Biomed Central 